\section{Targets work}

\section{Washington}

THE planned limits on greenhouse gases could cut the predicted global temperature rise by about half a degree by the year 2100 , according to a study commissioned by the US newsletter Global Environmental Change. But the total temperature rise during this period could be as much as $4{ }^{\circ} \mathrm{C}$, so the measures may not be enough significantly to slow global warming, the study by the Climatic Research Unit at the University of East Anglia (UEA), United Kingdom says.

By the end of this year, 22 industrialized nations - including almost all of the Organization for Economic Cooperation and Development (OECD) - will have adopted formal greenhouse gas stabilization or reduction targets. Assuming that all the countries stick to their goals, overall OECD greenhouse emissions
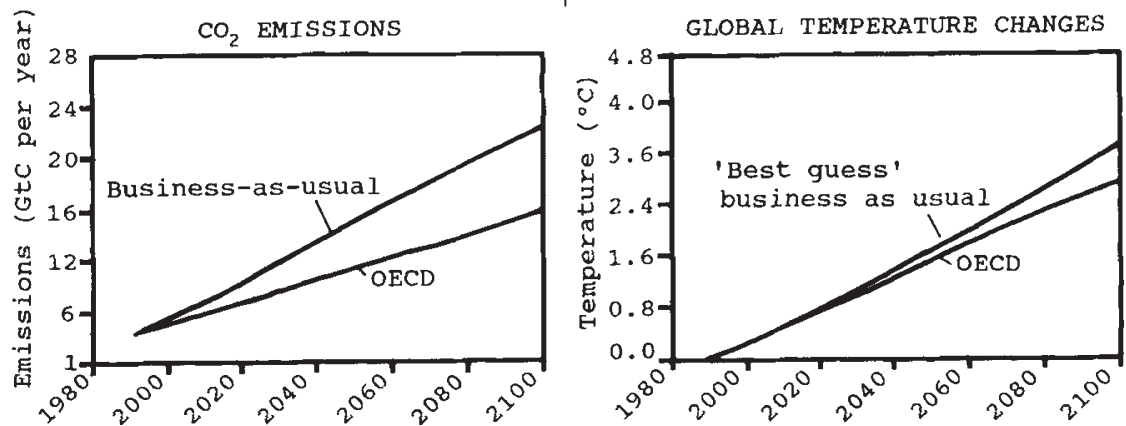

From the UEA study for the years 1980-2100. 'Business as usual' includes the revised Montrea Protocol cuts. OECD denotes effect of OECD greenhouse targets should drop 22 per cent by 2005, as measured by the World Resource Institutes' greenhouse index, which weights various gases by their carbon equivalents (see Nature 347, 705; 25 October 1990).

Of the OECD countries whose carbon dioxide output is large enough significantly to affect global trends, only the United States is expected to increase its carbon dioxide emissions in the next 15 years - by some 19 per cent over 1987 ARCTIC figures. But because the United States represents such a large fraction of OECD emissions, that increase is likely to increase total OECD carbon dioxide output by some 7 per cent over the same period, the study finds.

Even so, the predicted global output of greenhouse gases will fall over the period, reflecting the importance of chloroflurocarbons (CFCs) in the equation. CFC limits imposed by the Montreal Protocol are the single largest factor in the projected reduction of greenhouse gases. Atmospheric concentrations of greenhouse gases would continue to rise, however, as the rate of new emissions still exceeds natural dispersion.

The researchers at UEA who entered the projected emission figures into their 'STUGE' computer model, project that the OECD reductions would result in
The gang that couldn't shoot straight

\section{Washington}

IF you had wanted to break into one of the most sensitive US weapons research facilities, April 1989 would have been a perfect time. For that month, and for a few weeks on either side, the US Department of Energy (DoE) was guarding its classified Los Alamos National Laboratory with a security force that was a little soft on some of the basics - shooting, handcuffing and stopping intruders. Many of the guards, who were replacements brought in during a ten-week strike by the usual security force, had not been trained to use their weapons, and none were issued with batons because they were not qualified to use them. A congressional oversight committee notified $\mathrm{DoE}$ that it had received allegations of "many instances of firearms 'horseplay' by the replacement force". During a simulated entry attempt, the guards failed to find drug equipment.

But a subsequent investigation by the General Accounting Office (GAO), Congress's investigative arm, revealed that the temporary guards were hardly worse than the officers they replaced. In fact, as a surprise inspection earlier this year revealed, 78 per cent of the regular force "lacked one or more of the skills needed to arrest, apprehend, communicate, and survive in an adversarial situation; protect laboratory resources or staff; or defend themselves", says a report published last week.

During a series of unannounced simulated break-ins, many of the current Los Alamos guards "left thejr cover and walked up to the potential adversary to ask what they were doing. As a result, in many instances the adversary took a visible weapon, 'killed' the [guard], and left with the classified documents of government property", GAO reported. In total, 24 of the guards were "killed" during the testing.

DoE, according to the report, "recognizes that these problems exist not only at Los Alamos, but throughout the nuclear weapons complex". As a result, DoE has asked its central training academy to reexamine the training given to its security forces, and to develop a standard course for security guards. And DoE may consider trying some more unannounced tests. Although DoE policies allow for such tests, it had not conducted them in the past because, as DoE officials explained to the GAO, "they raise safety concerns, are difficult to plan, disrupt the work force, and create stress for all participants".

Christopher Anderson 